\title{
AN OVERVIEW OF HELICOBACTER PYLORI INFECTION AND ITS MYSTERY
}

\author{
Attah, $\mathrm{F}^{\mathrm{a} *}$, Mela, $\mathrm{M}^{\mathrm{b}}$., Garba D.E ${ }^{\mathrm{c}}$, Olarewaju, G.A. ${ }^{\mathrm{d}}$ and Ejiko, J ${ }^{\mathrm{e}}$. \\ ${ }^{a}$ Department of Microbiology, Federal University of Technology, Minna, Niger State, Nigeria. \\ ${ }^{\mathrm{b}}$ Department of Microbiology, Federal University Wukari, Taraba State, Nigeria. \\ ${ }^{\mathrm{c}}$ Department of Microbiology, University of Nigeria, Nsuka, Nigeria. \\ ${ }^{\mathrm{d}}$ Executive Director, Involve Community Engagement Initiative, Minna, Niger State, Nigeria \\ ${ }^{\mathrm{e}}$ Department of Medical Laboratory Technology, Kogi State College of Health Sciences and technology, Idah, Kogi State, Nigeria. \\ Corresponding author email: fridayata2014@gmail.com
}

\begin{abstract}
Helicobacter pylori (H. pylori) is a gram negative microaerophilic bacterium that infects the epithelial lining of the stomach and is associated with the development of peptic ulcers and cancer. Infection is more common in those with a lower socioeconomic status and is commonly acquired during infancy. There is no recognized route of infection, but fecal-oral and oral-oral contact has been associated with transmission from person to individual. There were no clinical signs in several individuals harboring the pathogens. The only viable bacterium that survived the acidic existence of the stomach due to the capacity of the organism to generate urease and other adaptive factors is Helicobacter pylori. A specific virulence factor affecting colonization and disease severity has been recognized: cytotoxin-associated (cagA) and vacuolating cytotoxin (vacA). The most recognized risk factor for peptic ulcer disease and gastric cancer is Helicobacter pylori. As a result of its resistance to antibiotics and false understanding of the infection by people, the burden of helicobacter pylori infection aggravated. Invasive and non-invasive approaches is used to detect it. Prevention of the organism is strictly by observation of proper hygiene and awareness. The endemicity of Helicobacter pylori call for early detection to avert the health implications.
\end{abstract}

Keywords; Helicobacter pylori; Peptic ulcer; virulent factor; stomach; inflammation; childhood and gastritis.

\section{Introduction}

Helicobacter pylori (H. Pylori) is a gram-negative microaerophilic bacterium that contaminates the epithelial covering of the stomach which is connected to the advancement of persistent gastritis, gastric ulcers, duodenal ulcers, and stomach mucosal decay (Olufemi et al., 2015; James et al., 2017). Helicobacter pylori is a predominant bacterium that is communicable. It was reported that over half of the total population of the world is contaminated with the microbes (Olufemi et al 2015; Mbang et al., 2019).

Shiotani and Graham (2002) reported that in the mid-1980s, Marshall and Warren first cultivated the bacterium. Peura et al. (2010) revealed that $H$. Pylori had a one of a kind winding shape and different unipolar flagella which empowers it to navigate the course of the mucous layer of the gastric epithelium, where it stays shielded from the low gastric secretion. The most well-known course of $H$. pylori contamination is either oral-oral or fecal-oral contact (Ayodele et al., 2018) and is usually obtained during infancy (Moayyedi et al., 2002).

The dispersion of $H$. pylori is affected by age, sex, geographical location, nationality and financial status (Hooi et al., 2017). The geographical location of $H$. pylori shows higher with low income nations when contrasted with the well to do nations particularly in more youthful ages. With a larger part of nations in Africa not yet developed (Smith et al., 2019).

H. pylori infection has been recognized as a significant risk factor for the advancement of peptic ulcer disease and is likely the most significant reason for reversion in those recently treated for peptic ulcer illness (Abubakar et al., 2015). Ulcer may cause dull or burning agony in the tummy. It might go back and forth, in any case, the agony is generally become genuine when the stomach is vacant, for example, between meals or in the night. It can keep going for a couple of moments or for quite a long time. latter, the person will feel better subsequent to eating, drink milk, or take a stomach settling agent (antacid) (Khatri, 2018), the first ulcer's drug of used (Malfertheiner and Schulz, 2020).

The bacterium varies hereditarily, able to overcome acidic gastric condition, and at present creates obstruction for many antimicrobials. However, epidemiological dispersion of $H$. pylori fluctuates internationally (Fasciana et al., 2015). In any case, H. pylori contamination is generally asymptomatic in its carriers, however when it influences human wellbeing, gastritis, gastric ulcers and duodenal ulcers can be prompted (Smith et al., 2019). 
The contributing Factors for colonization of the organism include motility, environmental sensing, chemotaxis, iron acquisition and acid resistance were reported by Chukwuma et al. (2020). And Virulence factors include the cytotoxinassociated gene (cag) pathogenicity island (PAI), which induces pro- inflammatory, pro-proliferative of epithelial cell signaling; the cytotoxin VacA, which causes epithelial impairment; and blood group antigen binding adhesin (BabA) (Chukwuma et al., 2020). The aim of this study was to revealed an overview of Helicobacter pylori infections and its mystery.

\section{The discovery and pathogenesis of $\mathrm{H}$. pylori and its survival strategy.}

The discovery of this silence monster, H. pylori as it was reported by Matsushima and Nagai (2012), began by German scientists who first noticed the bacterium which is spiral in shape in the lining of the gut of human in 1875 and was later defined by Marshall and Warren in 1984, who went on to associate the presence of $H$. pylori in the stomach to gastritis and ulceration of the stomach or duodenum (peptic ulcer disease). Twenty-one years ago, H pylori species genome sequence was completely made accessible freely for the first time (Shiotani et al., 2002). Six years later, Marshall and Warren were awarded the Nobel Prize in Physiology or Medicine for this discovery (Matsushima and Nagai, 2012).

H. pylori inhabit the mucus adjacent to the gastric mucosa (Correa and Piazuelo, 2008). However, the source of the H. Pylori had not been completely settled (Olczak et al., 2002), but after transmission, the bacteria reached and stayed in the stomach; the ecological niche of the bacterium where the $\mathrm{pH}$ tends to be very low owing to urease activity (Nwozor, 2013). Urea hydrolysis produces a basic domain that may shield the bacterium from corrosive. The organisms started to increase in gastric condition, which is unfriendly to the development of other microorganisms as revealed by Asali et al. (2018) (Fig 1). Other versatile highlights which are important for the survival of the organisms include its shape, motility, its attachment atoms that are trophic to certain gastric cells, its low oxygen requirement, its flagella and mucolytic catalysts which it produces to encourages its movement through the mucous layer to the gastric surface epithelium (Ajayi, 2015). Testerman and Morris (2014) also reported that another intriguing factor is non-poisonous lipopolysaccharide (LPS) in H. pylori, may add to determination by restricting the host provocative reaction. 


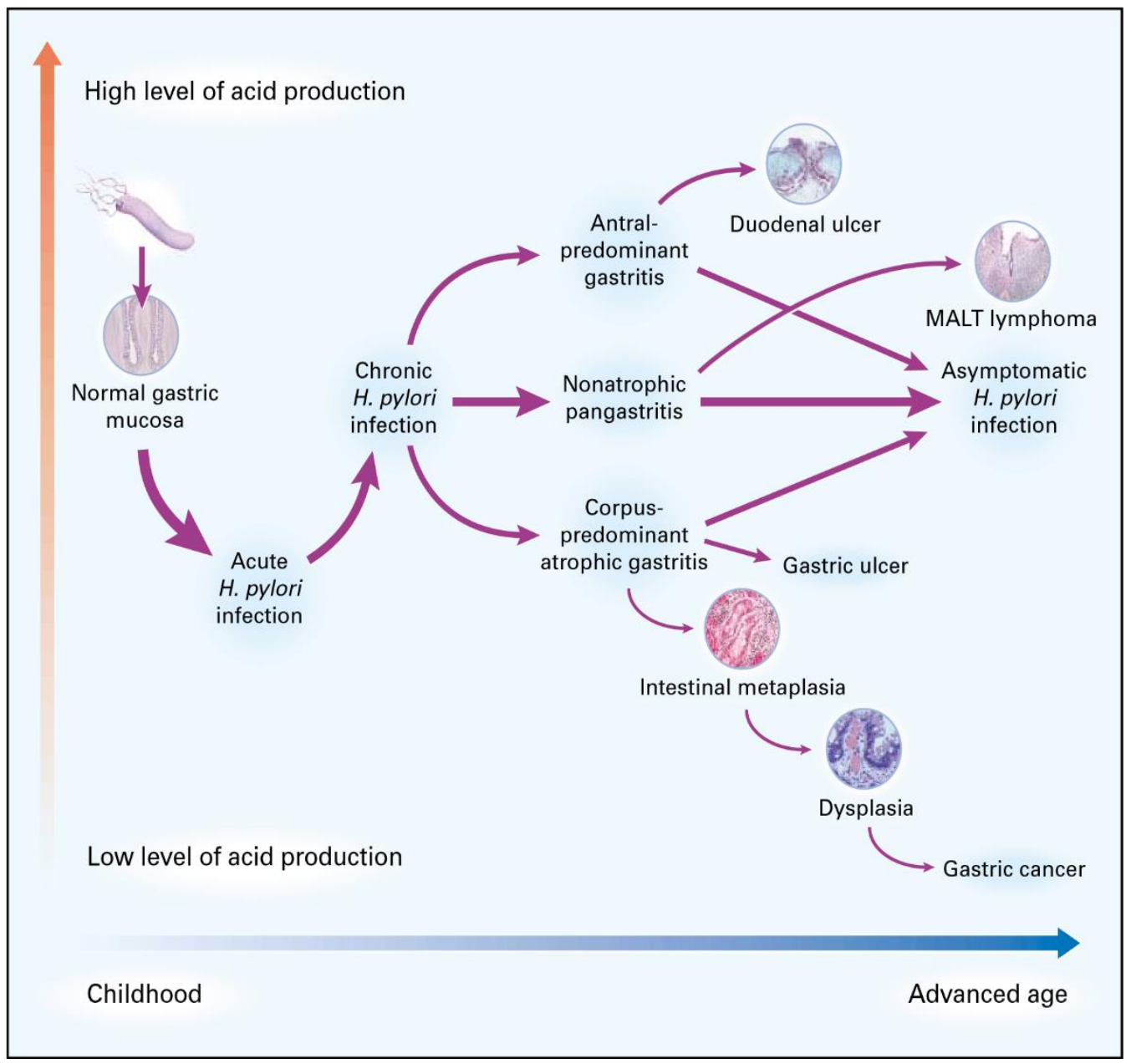

Source: Suerbaum and Michett, (2002)

Fig. 1. The pathogenesis of Helicobacter pylori infection

H. pylori infection occurred at childhood and there after lead to sequence of events for example: duodenal ulcer, gastric ulcer, and in rare cases, leads to gastric cancer and mucosa-associated lymphoid tissue as complication of $H$. pylori infection.

\section{Helicobacter pylori and its virulent factors}

Gonciarz et al., 2019) reported that the mechanism of $H$. pylori disease development is in stages: acute and chronic provocative responses. The presence of this organism may result in gastric/duodenal ulcers or gastric cancer growth. Extreme soreness induced by $H$. pylori can damage the gastric epithelial obstacle and its defensive role. Weakening of this function can help the translocation of $H$. pylori virulence factors and inflammatory mediators into the circulation, causing the development of a systemic inflammatory response (Gonciarz et al., 2019) (Fig. 1). Gastric cancer is divided into two: adenocarcinoma and lymphoma of gastric mucosal-associated lymphoid tissue (MALT) (Muzaheed, 2020). The latter is less common than the former (Muzaheed, 2020) (Fig 1).

H. pylori has been perceived with specific harmfulness factor which impact colonization and infection seriousness: the cytotoxin-related (cagA) and the vacuolating cytotoxin (vacA) (Correa and Piazuelo, 2008). H. pylori strains produce a protein CagA, which they inject into host cells resulting in changes in shape and surface characteristics of the cells. These changes represent a prelude to malignancy. Another bacterial product, VacA, acts on mucosal cells to promote flow of urea into the gut (Nwozor, 2013). CagA-positive H. pylori strains are related with more noteworthy irritation and expanded danger of ulcers malignant disease in the both people and animals (Kim et al., 2011). 
It has been firmly established that $H$. pylori first subverts innate immunity and then modulates the adaptive immune system (blocking the activation of both B and T cells) according report (Talebi, 2014). As a result, cagA and vacA, the main bacterial products, will inhibit $\mathrm{B}$ cell and $\mathrm{T}$ cell proliferation respectively. Accordingly, immune response in the stomach is silenced against digested microbes. Possibly, regulation and modulation of immune response arose after microbial exposure to $H$. pylori colonizing the stomach (Talebi, 2014).

\section{The role of $\boldsymbol{H}$. pylori in peptic ulcer}

According to Sverdén et al. (2019), Peptic ulcer disease (PUD) is frequently characterized as a tissue layer break more prominent than 3-5 metric linear unit within the abdomen or small intestine with a comprehensible profundity. Peptic ulcer illness presents with gastrointestinal indications like indigestion and can be hard to recognize clinically. PUD could be a typical problem over the globe. As indicated by the world Burden of sickness estimates, PUD was answerable for more than 300000 deaths in 2013 globally (Abubakar et al., 2015).

PUD is clinically delineated as a disturbance of the coherence of the duct tissue layer covering that show up as bruises of a minimum of $0.5 \mathrm{~cm}$ broad in examination investigations (Zibima et al., 2020). It's largely classified as stomach ulcers or small intestine ulcers base on the affected section of the gastrointestinal tract (GIT), follows gastric mucosal wounds owing to imbalance between the protecting and also the forceful variables influencing the mucous secretion (Asali et al., 2018). PUD is one in all the most well-known illnesses of the alimentary system (Zibima et al., 2020).

H. pylori infection has been recognized as a well-established risk factors for the advancement of peptic ulcer disease (Tijjani and Umar, 2008; Nwozor (2013). In a related study by Zibima et al. (2020), it was reaffirmed that PUD was mostly caused by the activities of $H$. Pylori.

Another issue that contribute to the development of ulcer but not as common as $H$. pylori is long-term use of certain medicines, including pain relievers such as ibuprofen, aspirin, and naproxen. These medicines are called NSAIDs, or non-steroidal anti-inflammatory drugs (Kumar et al., 2019). Factors like stress, spicy foods, alcohol, and smoking does not cause ulcers, but, they can keep it from healing quickly or make the pain worse. Symptoms of PUD include: abdominal pain, bloating, loss of appetite, weight loss, vomiting, nausea and heartburn (Nwozor, 2013).

\section{The predisposing factor of $\mathrm{H}$. pylori infection}

Helicobacter pylori is clearly the common sickness of developing countries (Negash et al. 2018). It colonizes 70-90\% of the populace in developing nations, while it is around half in developed nations (Graham, et al., 2014). In developing countries, an early childhood acquisition of H. pylori is between thirty to sixty (Negash et al. 2018).

The course by which contamination happens stays obscure, however various methods of transmission are accounted for (Dube et al., 2009). Person to person transmission of $H$. pylori through either fecal-oral or oral-oral appears to be doubtlessly (Perry et al., 2006). In any case, the risk of procuring $H$. pylori disease is identified with the financial status and living conditions early in life. Factors, for example, density of lodging, stuffing, number of kin, sharing a bed, messy condition and absence of running water particularly those that utilization well water have all been connected to a higher procurement pace of H. pylori disease (Awuku et al., 2017: Negash et al. 2018). de Brito et al. (2019) also added that the sharing of utensils was equally accounted for the transmission.

\section{The burden of $\boldsymbol{H}$. Pylori infection}

The burden ensuing from H. pylori infection is enormous. Haj et al. (2017) revealed that H. pylori causes persistent gastritis and small intestine ulcers, and in uncommon events gastric malignant growth and lymphoma, that typically develop throughout adulthood. Many studies have addressed the link between $H$. pylori infection and diabetes mellitus (DM), a medical condition ensuing from either duct gland not producing enough hypoglycemic agent, or cells of the body improperly responding to the insulin created as reported by Awuchi et al. (2020). Gastric irritation and damage to the gastric tissue layer can be at the bottom of a relationship between $H$. pylori disease and diabetes mellitus. However, the role of peptic ulcerations, that develop following persistent internal organ inflammation in DM, has seldom been assessed (Haj et al., 2017).

There has been advancement in understanding the prevalence of $H$. pylori in several societies and also the burden of both ulcer and cancer (Axon, 2014). The foremost common reason behind death was difficult peptic ulcer illness with 
3.5 deaths per 100,000 populations each year accounting for around $27 \%$ of the deaths from underdeveloped and developing countries carry the bulk burden of surgical emergencies and their capability to handle the matter is inadequate, they harbour $85 \%$ of peptic ulcer-related deaths (Axon, 2014).

H. pylori cause gastritis, a condition that includes aggravation of the stomach's coating. H. pylori contamination is likewise connected to stomach disease (Murrell, 2017). The stomach has a layer of bodily fluid that is intended to shield it from stomach corrosive. H. pylori attach this bodily fluid coating and leave part of the stomach presented to acid. Together, the microbes and the acid can bother the stomach, causing ulcers, gastritis, or stomach disease (Murrell, 2017).

Waskito et al. (2018) reported the relationship of expanded expression with histologic movement to malignancy that is additionally expanded when $H$. pylori is available. Stomach malignant growth is rare in those that have not had $H$. pylori illness (Marshall et al., 2008).

Smith et al., (2019) have reviewed that, in 1994, the International Agency for analysis on Cancer, associate arm of the world Health Organization (WHO) classified H. pylori as a category I carcinogen for gastric cancer (GC), a definition given for the very best cancer inflicting agent.

Beyond its role in many gastroduodenal disorders, H. pylori has been concerned in several extra-gastroduodenal manifestations, like disorder thrombocytopenic purpura, vessel diseases, chronic liver diseases and iron-deficiency anaemia (Graham et al., 2014). The mean blood serum Fe and ferritin levels of $H$. pylori negative cluster were considerably beyond those of $H$. pylori positive ones (Yucel et al., 2014) justify the iron-deficiency anaemia.

Another burden, apart from the above mention, is antimicrobial resistance of $H$. pylori (Malfertheiner and Schulz, 2020). this is a key factor related with eradication failure. But the prevalence of such resistance varies amongst different geographical areas and has increased globally (Smith et al., 2019). Some of these resistance maybe as a result of previous exposure to antibiotics (Attah et al., 2020).

Olokoba et al. (2013) reported that despite the introduction of the first, second and third line therapies for H. pylori eradication, the eradication rate has not reached $100 \%$. Antibiotic resistance is still a problem in many countries (Olokoba et al., 2013). Clarithromycin-and metronidazole-resistant are the most common antibiotic-resistant strains of H. pylori and lower resistance was found with tetracycline and amoxicillin (Muzaheed, 2020).

\section{Detection of $\boldsymbol{H}$. pylori}

H. pylori infections can be easily diagnosed by non-invasive strategies or by endoscopic biopsy of gastric mucosa (invasive). The non-invasive strategies incorporate the urea breath test, serologic tests, stool antigen measures and urine ELISA. (Mustapha et al., 2018). However, the most dependable method for detecting H. pylori infection is through testing of endoscopically obtained gastric mucosal biopsy with rapid urease test, histology and culture (Enitan et al., 2018)

Urea breath tests and stool antigen test are equally used to affirm cure of Helicobacter Pylori disease (Enitan et al., 2018). Moreover, patient's serum could likewise be tried for the presence of against $H$. pylori antibody (Enitan et al., 2018).

Culture isn't regularly performed in light of the fact that $H$ pylori is critical and difficult to culture. Nevertheless, as resistance to antibiotics increases, culture may eventfully become required to select nonresistant antibiotic therapy (Shiotani and Graham, 2002).

\section{The prevention of $\boldsymbol{H}$. pylori infection.}

As with other enteric infections, $H$. pylori infection rates have decreased dramatically with improvements in sanitary infrastructure and household hygienic practices (Yucel et al., 2014). Personal hygiene is very important since contaminated food and dirty water may be potential sources of infection (Hunt, 2011).

According to Murrell (2017), there is no known way to prevent $H$. pylori infection, however, he recommended the followings:

- Washing hands before eating and after using the restroom.

- Eating food that has been handled and prepared safely. 
- Drinking only clean, safe water.

Of course, these are true with most infection diseases especially those that are transmitted orally.

\section{Conclusion}

Helicobacter pylori infection is endemic globally which prevalence is high with underdeveloped and developing countries as applicable to other infectious agents. Failure to detect the infection early and its resistance to antibiotics lead to a serious health burden. People from low income countries suffering from the symptom of peptic ulcer and other intestinal conditions should not jump to conclusion that the condition is as a result of stress, hungry, smoking, alcohol and certain food. Test should precede any medication in order to avoid complication that may arise owing to wrong treatment. Helicobacter pylori may not be the sole causes of these conditions, however, $70 \%$ to $90 \%$ of it are caused by the organism.

Since the mode of transmission remained oral-oral and fecal-oral, it is therefore imperative to observe environmental cleanness and equally ensured that municipal water and food are safe before consumption.

\section{Conflict of interest}

The authors hold no contrary opinion to the works of others as regarding to this present review.

\section{Acknowledgement}

It will be unfair not recognizing the contribution of others. We give kudos to Mr. Achor O.M of Federal Polytechnic Idah (FPI) for his assistance. We also give thanks to Jeremiah Ejiko of Kogi State College of Health Sciences and Technology, Idah for his contribution.

\section{Reference}

Abubakar, I. I., Tillmann, T., and Banerjee, A. (2015). Global, regional, and national age-sex specific all-cause and cause-specific mortality for 240 causes of death, 1990-2013: a systematic analysis for the Global Burden of Disease Study 2013. Lancet, 385(9963), 117-171.

Ajayi, E.O. (2015). The Prevalence of Helicobacter Pylori Infection Using Stool Antigen in Apparently Healthy Nigerian Secondary School Children in Surulere LGA, Lagos State. Published Thesis.www.dissertation.npnmcn.edu.ng/index.php/FMCPaed/article/view. Accessed 5 ${ }^{\text {th }}$ November, 2020.

Akinlua, J.T, Meakin R, Umar, A.M and Freemantle N (2015) Current Prevalence Pattern of Hypertension in Nigeria: A Systematic Review. PLoS ONE 10(10): e0140021.

Asali, A. M., Alghamdi, M. A., Fallatah, S. A., Alholaily, W. A., Aldandan, R. G., Alnosair, A. H. and Alharbi, R. A. (2018). Risk factors leading to peptic ulcer disease: systematic review in literature. International Journal Community Med Public Health, 5, 4617-24.

Attah, F., Angulu, C. N., Mamman, G., Udensi, E., Anyebe, E. O., Daniel, E. N. and Olaruwaju, G. A. (2020). Rising Cases of Antibiotics Self-medication and its Associated Predicament. Fudma Journal of Sciences, 4(3), 668671.

Awuchi, C.G., Echeta, C.K., and Igwe, V.S (2020). Diabetes and the Nutrition and Diets for Its Prevention and Treatment: A Systematic Review and Dietetic Perspective. Health Sciences Research, 6(1), 5-19.

Awuku, Y.A., Simpong, D.L., Alhassan, I.K., Tuoyire. D.A., Afaa, T. and Adu, P. (2017). Prevalence of helicobacter pylori infection among children living in a rural setting in Sub-Saharan Africa. BMC Public Health, 17(360), $1-6$

Axon, A. (2014). Helicobacter pylori and public health. Helicobacter, 19, 68-73.

Ayodele, M.B.O., Aaron, U.U., Oluwatayo, G.A., and Wariso, K.T. (2018). Prevalence of Helicobacter pylori infection among suspected peptic ulcer patients in Port Harcourt, South-South, Nigeria. Gazette of Medicine, $6(1), 602-608$ 
Chukwuma, O., Chukwuma, G.O, Manafa, P.O, Akulue, J.C. and Jeremiah, Z.A. (2020). Prevalence and Possible Risk Factors for Helicobacter pylori Seropositivity among Peptic Ulcerative Individuals in Nnewi Nigeria. BioMed Research Journal (BMRJ), 4(1), 166-172

Correa, P and Piazuelo, M.B. (2008). Natural History of Helicobacter Pylori Infection. Dig Liver Dis. 40(7): 490496.

de Brito, B. B., da Silva, F. A. F., Soares, A. S., Pereira, V. A., Santos, M. L. C., Sampaio, M. M. and de Melo, F. F. (2019). Pathogenesis and clinical management of Helicobacter pylori gastric infection. World journal of gastroenterology, 25(37), 5578.

Dube, C, Tanih, N.F., Clarke, A.M., Mkwetshana, N., Green, E and Ndip, R.N. (2009). Helicobacter pylori infection and transmission in Africa: Household hygiene and water sources are plausible factors exacerbating spread. African Journal of Biotechnology, 8 (22), 6028-6035

Enitan S.S, Ochei J.O, Akele, Y.R, Faloye, T.G, Adeniyi, L.O, and Omotola, D (2018). Screening for Helicobacter Pylori Infection among Undergraduate Students of a Tertiary Institution using serum Antibody and Stool Antigen Detection Methods. Biomed J Sci \&Tech Res 3(2), 3180-3189

Fasciana, T., Calà, C., Bonura, C., Di Carlo, E., Matranga, D., Scarpulla, G. and Giammanco, A. (2015). Resistance to clarithromycin and genotypes in Helicobacter pylori strains isolated in Sicily. Journal of Medical Microbiology, 64(11), 1408-1414.

Gonciarz W, Krupa A, Hinc K, Obuchowski M, Moran AP, Gajewski A, et al. (2019). The effect of Helicobacter pylori infection and different $H$. pylori components on the proliferation and apoptosis of gastric epithelial cells and fibroblasts. PLo SONE 14(8): e0220636.

Graham, D. Y. (2014). History of Helicobacter pylori, duodenal ulcer, gastric ulcer and gastric cancer. World Journal of Gastroenterology: WJG, 20(18), 5191- 5204

Graham, D. Y., \& Yamaoka, Y. (1998). H. pylori and cagA: relationships with gastric cancer, duodenal ulcer, and reflux esophagitis and its complications. Helicobacter, 3(3), 145-151.

Graham, D. Y., Lee, Y. C., \& Wu, M. S. (2014). Rational Helicobacter pylori therapy: evidence-based medicine rather than medicine-based evidence. Clinical Gastroenterology and Hepatology, 12(2), 177-186.

Haj S, Chodick G, RefaeliR, Goren S, Shalev V, Muhsen, K. (2017). Associations of Helicobacter pylori infection and peptic disease with diabetic mellitus: Results from a large population-based study. PLoSONE 12(8), e0183687.

Hooi, J. K., Lai, W. Y., Ng, W. K., Suen, M. M., Underwood, F. E., Tanyingoh, D. and Chan, F. K. (2017). Global prevalence of Helicobacter pylori infection: systematic review and meta-analysis. Gastroenterology, 153(2), 420-429.

Hunt, R. H., Xiao, S. D., Megraud, F., Leon-Barua, R., Bazzoli, F., Van der Merwe, S. and Malfertheiner, P. (2011). World Gastroenterology Organisation Global Guidelines Helicobacter pylori in developing countries August 2010: WGO global guidelines. South African Gastroenterology Review, 9(3), 16-22.

John, I.O., Ikpeama C.A., Ikpeama C.J, Okafor, P.A. Ibeh, I.N, Igbineweka, O.O, Ikpeama E.A, Ofuenyi, J.G., Chukwudi, M, Ogwuegbu J.U., et al. (2018). Burden of Helicobacter Pylori (H. Pylori) Disease in a Community in Sokoto State. Archives of Immunology and Allergy. 1(2), 25-30.

Khatri, M. (2018). What is H. pylori? www.Webmd.com/digestive-diorders/h-pylori-helicobacter-pylori. Accessed on $4^{\text {th }}$ October, 2020

Kim, S. S., Ruiz, V. E., Carroll, J. D. and Moss, S. F. (2011). Helicobacter pylori in the pathogenesis of gastric cancer and gastric lymphoma. Cancer letters, 305(2), 228-238.

Kumar, A., Ashwlayan, V., and Verma, M. (2019). Diagnostic approach \& pharmacological treatment regimen of Peptic Ulcer Disease. Pharm Res Open Access J, 1(1), 1-12. 
Malfertheiner, P and Schulz, C. (2020). Peptic Ulcer: Chapter Closed? Digestive Disease, 38:112-116.

Marshall, B., Stenström, B. and Mendis, A. (2008). Helicobacter pylori: The latest in diagnosis and treatment. Australian Family Physician, 37(8), 608-612.

Matsushima, K and Nagai, S (2012). Unraveling the mystery of the hygiene hypothesis through Helicobacter pylori infection, The Journal of Clinical Investigation, 122(3), 801-804.

Mbang, K. A., Uchenna, O., Emmanuel, U., Aniekan, E., Evaristus, C., Donald, E., and Ogbu, N. (2019). Prevalence of Helicobacter pylori infection among dyspepsia patients in Calabar. Global Journal of Pure and Applied Sciences, 25(2), 145-151.

Moayyedi, P., Axon, A.T, and Feltbolwer, R. (2002). Relation of adult lifestyle and socioeconomic factors to the prevalence of Helicobacter pylori infection. Int J Epidemiol., 31, 624-631.

Murrell, D (2017). What's to know about H. pylori. www.medicalnewstoday.com/articles/311636\#antibioticsresistance. Accessed on $4^{\text {th }}$ October, 2020

Mustapha, S., Pindiga, U., Yusuph, H., Goni, B., and Jibrin., Y. (2010). Helicobacter Pylori Infection Among Dyspeptic Patients at A Tertiary Hospital in Northern Nigeria. The Internet Journal of Infectious Diseases, 9(2), 1-4.

Muzaheed, M (2020). Helicobacter pylori Oncogenicity: Mechanism, Prevention, and Risk Factors. Scientific World Journal. Scientific World Journal, https://doi.org/10.1155/2020/3018326.

Negash, M., Wondifraw B., H. and Geremew, D. (2018). Helicobacter pylori Infection and Its Risk Factors: A Prospective Cross-Sectional Study in Resource-Limited Settings of Northwest Ethiopia. Canadian Journal of Infectious Diseases and Medical Microbiology, 1-7.

Nwozor, C.M. (2013). The Role of Helicobacter pylori in Peptic Ulcer Disease. Greener Journal of Medical Sciences, $3(6), 222-227$

Olczak, A. A., Olson, J. W., and Maier, R. J. (2002). Oxidative-stress resistance mutants of Helicobacter pylori. Journal of bacteriology, 184(12), 3186-3193.

Olokoba, A. B., Obateru, O. A. and Bojuwoye, M. O. (2013). Helicobacter pylori eradication therapy: A review of current trends. Nigerian medical Journal: Journal of the Nigeria Medical Association, 54(1), 1-4.

Olufemi, F.O., Quadri R., Akinduti, P.A. and Bamiro, S.A. (2015). Potential Risk Factors and Prevalence of Infection of Helicobacter pylori in Nigeria. Journal of Scientific Research \& Reports, 7(1), 42-48

Perry, S., De La Luz Sanchez, M., Yang, S., Haggerty, T. D., Hurst, P., Perez-Perez, G. and Parsonnet, J. (2006). Gastroenteritis and transmission of Helicobacter pylori infection in households. Emerging infectious diseases, 12(11), 1701.

Peura, D.A, and Crowe S.E. (2010). Helicobacter pylori. In: Feldman M, Friedman, L.S, Brandt LJ (Editors) Sleisenger and Fordtran's Gastrointestinal and Liver Disease; Pathophysiology, Diagnosis, Management, Vol. II, Saunders Elsevier. 833- 839.

Shiotani, D.Y. A. and Graham, D.Y. (2002). Pathogenesis and therapy of gastric and duodenal ulcer disease. Medical Clinic of North America, 86, 1447-1466

Smith, S., Fowora, M., and Pellicano, R. (2019). Infections with Helicobacter pylori and challenges encountered in Africa. World journal of gastroenterology, 25(25), 3183-3195'

Suerbaum, S and Michett, P (2002), Helicobacter pylori infection. New England Journal of Medicine, 347(15): 11751186.

Sverdén, E., Agréus, L., Dunn, J.M. and Lagergren, J. (2019). Peptic ulcer disease. BMJ, 367(15495), 1-8

Talebi B.A.A. (2014). Helicobacter pylori: a beneficial gastric pathogen? Frontiers in medicine, 1, 26. 
Testerman, T. L. and Morris, J. (2014). Beyond the stomach: an updated view of Helicobacter pylori pathogenesis, diagnosis, and treatment. World journal of gastroenterology: WJG, 20(36), 12781-12808.

Tijjani B, and Umar A (2008) Peptic Ulcer Disease and Helicobacter Infection at Kano, Nigeria. The Internet Journal of Gastroenterology, 8(1), 1-4.

Waskito, L. A., Salama, N. R., and Yamaoka, Y. (2018). Pathogenesis of Helicobacter pylori infection. Helicobacter, 23, e12516.

Yucel, O. (2014). Prevention of Helicobacter pylori infection in childhood. World journal of gastroenterology: WJG, 20(30), 10348-10354

Zibima, S. B., Oniso, J. I. and Wasini, K. B. (2020). Prevalence Trends and Associated Modifiable Risk Factors of Peptic Ulcer Disease among Students in a University Community South-South Nigeria. International Journal of Health Sciences and Research, 10(6), 97-105. 